\title{
Namnožitev poljske zapredkarice (Cephalcia arvensis) v Sloveniji
}

\section{Maja JURC*}

O izbruhu zapredkaric iz rodu Cephalcia (Hymenoptera-kožekrilci: Symphyta-rastlinske ose, Pamphiliidae-zapredkarice ali prelke) smo poročali v drugi številki NVG leta 2009. Opazili so ga gozdarji v začetku julija 2009 v OE Slovenj Gradec, GGE Ravne. Namnožitev zapredkaric se je pojavila na pobočjih nad zahodnim delom Prevalj na Riflovem vrhu na površini 48 ha ter na nadmorski višini med 600-800 m. Zapredkarice so na vejah od 60 do 90 let starih, predvsem vitalnih smrek, oblikovale velike, rahle zapredke iz svojih iztrebkov v katerih poteka razvoj ličink. Na omenjeni lokaciji smo nadaljevali raziskave vrstne sestave zapredkaric, njihove bioekologije ter vplive na smrekov sestoj.

Za vrste rodu Cephalcia je značilna velika variabilnost $\mathrm{v}$ dolžini življenjskega kroga in za dokončanje razvoja potrebujejo 1-4 leta, občasno tudi 5-6 let. Dolžina razvojnega kroga je pomemben dejavnik populacijske dinamike in od poznavanja dolžine razvojnega kroga je, med drugimi dejavniki, odvisna tudi napoved izbruha zapredkaric. Leta 2009 se je v namnožitvi pojavila poljska zapredkarica Cephalcia arvensis Pancer, 1805. Vrsto smo določili na osnovi morfoloških značilnosti odraslih osebkov, ki so bili nabrani 27. 4. 2012. Določitev je potrdil prof. Andrea Battisti iz Univerze v Padovi. Menimo, da je ta vrsta prevladovala, po poškodbah in značilnostih starejših ličink in predpupalnih oblik lahko sklepamo, da je bila prisotna tudi smrekova zapredkarica Cephalcia abietis Linnaeus, 1758.

\section{Biologija poljske zapredkarice}

Adultna faza. Poljska zapredkarica je rojila v Prevaljah konec aprila in maja (ko cvetijo črnice - borovnice). Po literaturi se pojavlja Cephalcia arvensis v dveh oblikah: "pomladanska oblika", ki roji zgodaj, med majem in junijem in tako rojenje traja 30-40 dni, in "poletna oblika" zapredkarice, ki roji samo avgusta. Odrasli osebki se pojavijo, ko se temperatura dvigne do okoli $12{ }^{\circ} \mathrm{C}$. Prehranjujejo se s sladkimi sokovi, predvsem mano. Samci rojijo en teden pred samicami, navadno so pri tleh, letijo in plezajo po rastju. Samice so na tleh, plezajo na rastline in letijo na krajše razdalje. Kopulacija se dogaja na tleh, traja 1-5 min.

Faza jajčec. Samice lahko živijo do enega meseca, ležejo jajčeca skozi celotno življenjsko obdobje, največ pa v prvem tednu svojega življenja. Samice odložijo v povprečju 22-24 jajčec, večinoma posamično (pri večji gostoti populacije odlagajo do tri jajčeca skupaj) na enoletne iglice, v zgornjem in srednjem delu krošnje. Iz zelenkasto sivkastih jajčec se po 12-20 dneh izležejo larve.

Faza ličink. Razvoj ličink traja, v odvisnosti od vremenskih razmer, 30-45 dni, larve samcev se levijo štiri krat, larve samic pa pet krat. Povprečna velikost larv je: $\mathrm{L}_{1}$ 0,87 mm, $\mathrm{L}_{2}$ 1,14 mm, $\mathrm{L}_{3} 1,54 \mathrm{~mm}, \mathrm{~L}_{4}$ 1,85 mm, $\mathrm{L}_{5}$ 2,18 mm. Živijo izolirano, v skupinskih zapredkih, v svilnatih cevkah, ki so pripete na iglice smreke. Larve zapustijo zapredke zaradi prehranjevanja, hrano privlečejo v zapredek in jo zaužijejo. Prehranjujejo se s starejšimi iglicami, iglice tekoče vegetacije žrejo le v pomanjkanju starejših iglic. Raziskave so pokazale, da v ujetništvu vsaka ličinka porabi 80120 iglic. Na koncu razvoja nekatere larve spremenijo barvo iz rjavo rdeče $\mathrm{z}$ vzdolžnimi belimi progami $\mathrm{v}$ enotno rumeno ali zeleno. Zeleni osebki obsegajo 1-5 \% populacije. Obdobje spuščanja ličink v tla traja en mesec, od konca julija do konca avgusta.

Podzemna faza (eonimfe, pronimfe in bube) (slika 1, 2, 3). Cephalcia arvensis prebije večji del svojega razvoja pod zemljo kot predbuba (eonimfa in pronimfa) v kamricah, ki so narejene iz prsti. Odrasle larve, se takoj ko dosežejo tla zarijejo v vrhnjo plast tal (A horizont). Tam samice izdelajo $7 \times 12 \mathrm{~mm}$ velike ovalne kamrice, samci pa $6 \times 9$ mm velike kamrice. Predpupe, ki diapavzirajo v tleh, so lahko dveh oblik, eonimfe in pronimfe. Podaljšana diapavza eonimfe se pojavlja $\mathrm{v}$ tistih primerih, ko je pri selitvi ličinke $\mathrm{v}$ tla temperatura pod $12{ }^{\circ} \mathrm{C}$. V tem primeru, torej pri nizkih temperaturah, se eonimfe spremenijo $\mathrm{v}$ pronimfe $\mathrm{v}$ naslednjem poletju in razvoj traja dve leti. V drugem primeru, ko je temperatura tal pri selitvi larv v tla nad $12{ }^{\circ} \mathrm{C}$, pa se larve takoj spremenijo $\mathrm{v}$ pronimfe in odrasli osebki se pojavijo v naslednji pomladi. Globina, ki jo zrele larve dosežejo $\mathrm{v}$ tleh, je proporcionalna velikosti larv in obratno proporcionalna temperaturi tal. Torej, voltinizem (trajanje razvoja živalske vrste) je odvisen od temperaturnih razmer, ki vladajo v krošnjah gostiteljskih dreves in od temperatur različnih plasti tal.

Eonimfe so svetlejše in bolj gibljive kot pronimfe, nimajo razvitih oči, sposobne so ponovno oblikovati kamrice (v primeru, da je kamrica poškodavana) in nimajo razvitih gonad. Pronimfe so skoraj nepremične, imajo razvite gonade in oči, niso sposobne ponovne gradnje kamric. Razvoj bube, ki poteka spomladi iz pronife v kamrici, traja 15-20 dni, pri bubah lahko ugotovimo spol po genitalnem segmentu.

Adulti ostanejo nekaj dni v kamrici pred eklozijo (izleganjem) in se nato pojavijo na tleh in pritalni vegetaciji sestoja.

Poznavanje biologije poljske zapredkarice je pomembno za predvidevanje pojava namnožitve te vrste v naravi. Za uspešno prognozo so nujni točni podatki o temperaturi tal pri prehodu ličink v tla.

\section{Zahvala}

Za potrditev določitve vrste se zahvaljujemo prof. dr. Andrea Battisti, Universita di Padova, DAFNAEEntomologia, Agripolis - Viale dell'Universita 16, 35020 Legnaro PD, Italia, za nabiranje vzorcev pa Gregorju Metercu, univ. dipl. inž. gozd. 


\section{Viri}

Battisti A. 1993. Bionomics of the spruce web-spinning sawfly $\mathrm{Ce}$ phalcia arvensis Pancer (Hym., Pamphiliidae) in Northeastern Italy. J. Appl. Ent, 115: 52-61.

Battisti A. 1994. Voltinism and diapause in the spruce web-spinning sawfly Cephalcia arvensis. Entomol. exp.appl., 70: 105-113.

Beneš K. 1976. Revision of the European species of the genus Cephalcia Panzer, 1805 (Hym., Pamphiliidae). Studie ČSAV 2: 1-67.

Escherich K. 1942. Die Forstinsekten Mitteleuropas. Hymenoptera (Hautflügler) und Diptera (Zweiflügler). V Band. Berlin, Verlagsbuchhandlung Paul Parey: 746 str.

Jurc M. 2009. Predhodno poročilo o pojavu zapredkaric (Pamphiliidae:Cephalcia) na vejah navadne smreke na Koroškem. Ljubljana: Poročevalska, diagnostična in prognostična služba za varstvo gozdov, Gozdarski inštitut Slovenije, Oddelek za gozdarstvo in obnovljive gozdne vire BF: 5 str.

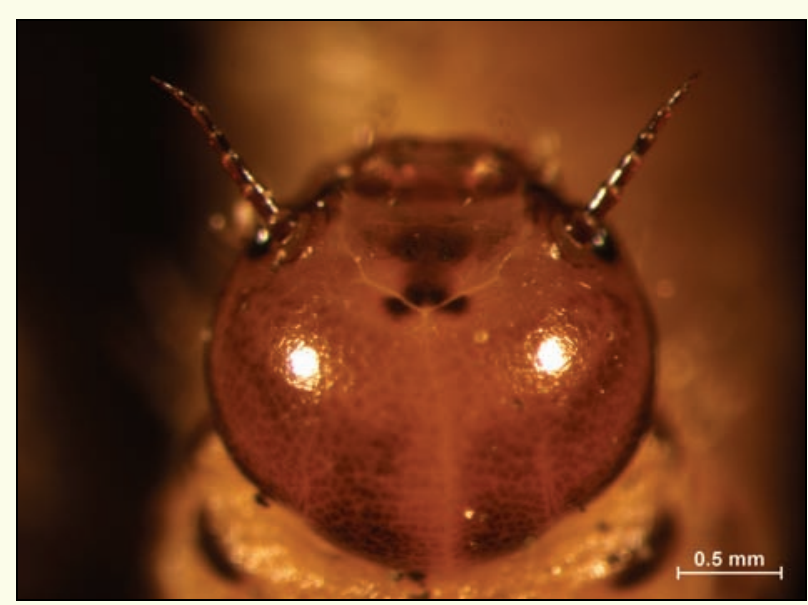

Slika 1: Poljska zapredkarica (Cephalcia arvensis), arhitektura glave predpupalne oblike (foto D. Jurc)

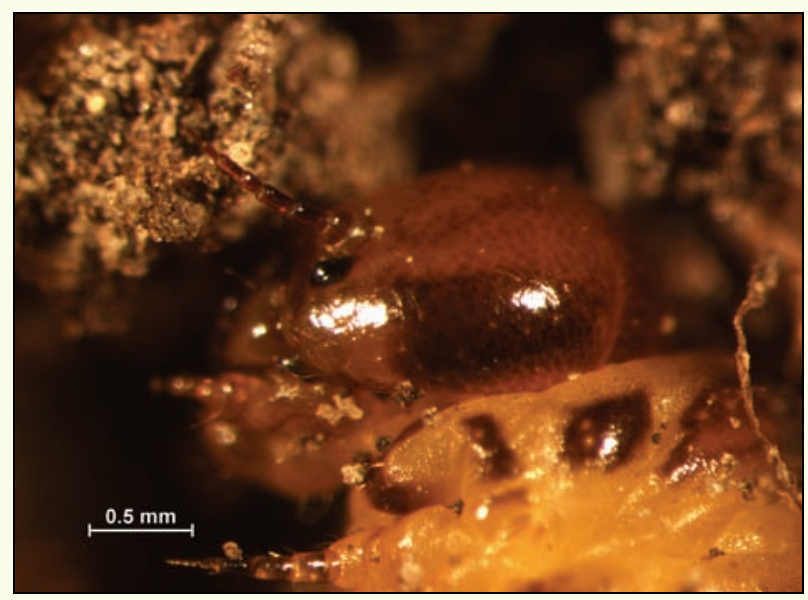

Slika 3: Glava starejše pronimfe poljske zapredkarice
Jurc M., Mlinšek G. 2009. Zapredkarice (Cephalcia spp.) na vejah navadne smreke na Koroškem pri Prevaljah. Novice iz varstva gozdov, 2 (9):

http://www.zdravgozd.si/nvg/prispevek.aspx?idzapis=2-9

Pschorn-Walcher H. 1982. Symphyta, Planzenwespen. In: Die Forstschädlinge Europas. Bd. 4. Ed.by W. Schwenke. Hamburg u. Berlin: Verlag Paul Parey: 188-191.

Schwenke W. 1982. Die Forstschädlinge Europas- Hautflüger und Zweiflügler. Band 4., Hamburg and Berlin, Verlag Paul Parey: 392.

*Univerza v Ljubljani, Biotehniška fakulteta, Oddelek za gozdarstvo in obnovljive gozdne vire, Večna pot 83, 1000 Ljubljana maja.jurc@bf.uni-lj.si

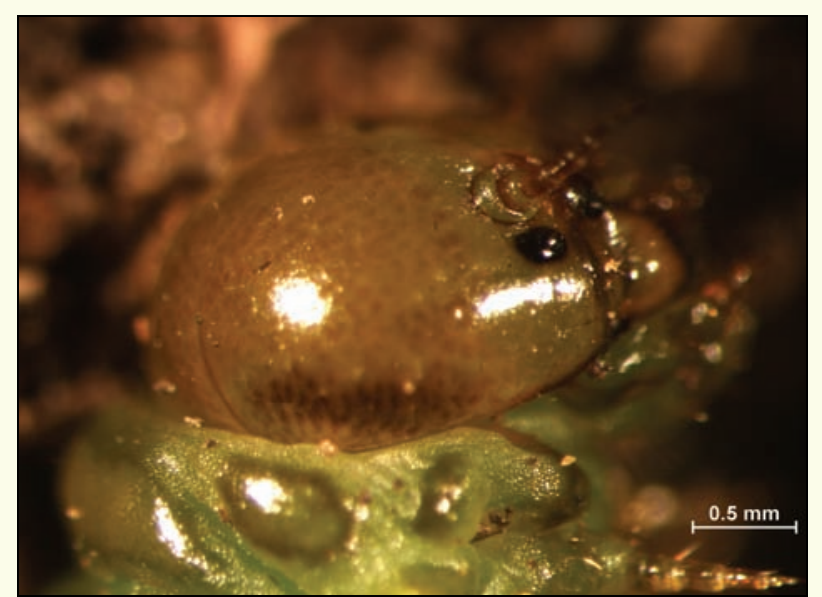

Slika 2: Glava mlajše pronimfe poljske zapredkarice 